\title{
Mechanisms of pathogenesis induced by bovine leukemia virus as a model for human T-cell leukemia virus
}

\author{
Yoko Aida ${ }^{1}$, Hironobu Murakami ${ }^{1,2}$, Masahiko Takahashi ${ }^{3}$ and Shin-Nosuke Takeshima \\ ${ }^{1}$ Viral Infectious Diseases Unit, RIKEN, Wako, Saitama, Japan \\ ${ }^{2}$ Laboratory of Animal Health II, Azabu University, Sagamihara, Kanagawa, Japan \\ ${ }^{3}$ Division of Virology, Niigata University Graduate School of Medical and Dental Sciences, Niigata, Japan
}

\section{Edited by:}

Akio Adachi, The University of

Tokushima Graduate School, Japan

\section{Reviewed by:}

Toshiki Watanabe, The University of Tokyo, Japan

Takeo Ohsugi, Kumamoto University, Japan

\section{*Correspondence:}

Yoko Aida, Viral Infectious Diseases Unit, RIKEN, 2-1 Hirosawa, Wako,

Saitama 351-0198, Japan

e-mail: aida@riken.jp
Bovine leukemia virus (BLV) and human T-cell leukemia virus type 1 (HTLV-1) make up a unique retrovirus family. Both viruses induce chronic lymphoproliferative diseases with BLV affecting the B-cell lineage and HTLV-1 affecting the T-cell lineage. The pathologies of BLV- and HTLV-induced infections are notably similar, with an absence of chronic viraemia and a long latency period. These viruses encode at least two regulatory proteins, namely, Tax and Rex, in the pX region located between the env gene and the $3^{\prime}$ long terminal repeat. The Tax protein is a key contributor to the oncogenic potential of the virus, and is also the key protein involved in viral replication. However, BLV infection is not sufficient for leukemogenesis, and additional events such as gene mutations must take place. In this review, we first summarize the similarities between the two viruses in terms of genomic organization, virology, and pathology. We then describe the current knowledge of the BLV model, which may also be relevant for the understanding of leukemogenesis caused by HTLV-1. In addition, we address our improved understanding of Tax functions through the newly identified BLVTax mutants, which have a substitution between amino acids 240 and 265.

Keywords: BLV, HTLV-1, EBL, B-cell lymphoma, Tax, leukemogensis, transactivation, apoptosis

\section{INTRODUCTION}

Bovine leukosis was first reported in 1871 as the presence of slightly yellow nodules in the enlarged spleen of cattle (Leisering, 1871). Spleen disruption consecutive to tumor formation is one of the most important clinical manifestations of bovine leukemia. Bovine leukosis is classified into two types, sporadic bovine leukosis (SBL) and enzootic bovine leukosis (EBL), which are characterized by $\mathrm{T}$ - and $\mathrm{B}$-cell leukosis, respectively (Gillet et al., 2007). The occurrence of EBL in cattle is much higher than that of SBL (Theilen and Dungworth, 1965; Onuma et al., 1979). Bovine leukemia virus (BLV), which belongs to the Retroviridae family and Deltaretrovirus genus, is the etiologic agent of EBL, although it remains unknown what causes SBL (Gillet etal., 2007). The natural hosts of BLV are domestic cattle and water buffaloes; however, experimental infection with BLV in sheep can lead to the development of lymphoma (Djilali and Parodi, 1989). Interestingly, BLV is consistently associated with leukemia only in cattle and sheep, even though it can infect many cell lines (Graves and Ferrer, 1976) and can be experimentally transmitted to rabbits (Wyatt etal., 1989; Onuma et al., 1990), rats (Altanerova et al., 1989), chickens (Altanerova et al., 1990), pigs, goats, and sheep (Mammerickx et al., 1981). Most BLV-infected cattle are asymptomatic, but approximately one-third of them suffer from persistent lymphocytosis (PL) characterized by non-malignant polyclonal B-cell expansion and $1-5 \%$ of them develop B-cell leukemia/lymphoma after a long latency period (Gillet et al., 2007). On the other hand, sheep that are experimentally inoculated with BLV develop B-cell tumors at a higher frequency and with a shorter latency period than those observed in naturally infected cattle (Ferrer etal., 1978; Burny etal., 1979; Kenyon et al., 1981; Aida etal., 1989). Interestingly, the transformed B-lymphocytes in cattle are $\mathrm{CD}^{+} \mathrm{IgM}^{+}$B-cells (Aida etal., 1993), whereas in sheep they are $\mathrm{CD}^{-} \mathrm{IgM}^{+}$B-cells (Murakami etal., 1994a,b), suggesting that the mechanisms of leukemogenesis induced by BLV may differ (Graves and Ferrer, 1976; Djilali and Parodi, 1989).

BLV is closely related to human T-cell leukemia virus type 1 (HTLV-1), which is the causative agent of adult T-cell leukemia (ATL) and a chronic neurological disorder known as tropical spastic paraparesis or HTLV-1-associated myelopathy HAM/TSP (Gessain et al., 1985; Osame et al., 1986; Gillet et al., 2007). Therefore, studies on BLV may facilitate our understanding of the mechanism of leukemogenesis induced by HTLV-1.

\section{BLV AND HTLV-1}

All retroviruses are encoded by gag, pro, pol, and env essential genes, which are necessary for the production of infectious virions, and are flanked by two identical long terminal repeats (LTRs; Figure 1). The gag, pro, pol, and env genes encode the internal structural proteins of the virion, the viral protease, the reverse transcriptase, and the envelope glycoproteins of the virion, respectively. The genome sequences of BLV and HTLV-1 are different, but have a unique sequence called the $\mathrm{pX}$ situated between the env gene and the $3^{\prime}$ LTR and encoded by the regulatory gene (Figure 1 ). The $\mathrm{pX}$ sequence is not of host cell origin; that is, it is not an oncogene. It has been reported that both viruses have an ability to immortalize primary cells in vitro (Grassmann et al., 1989; Willems 


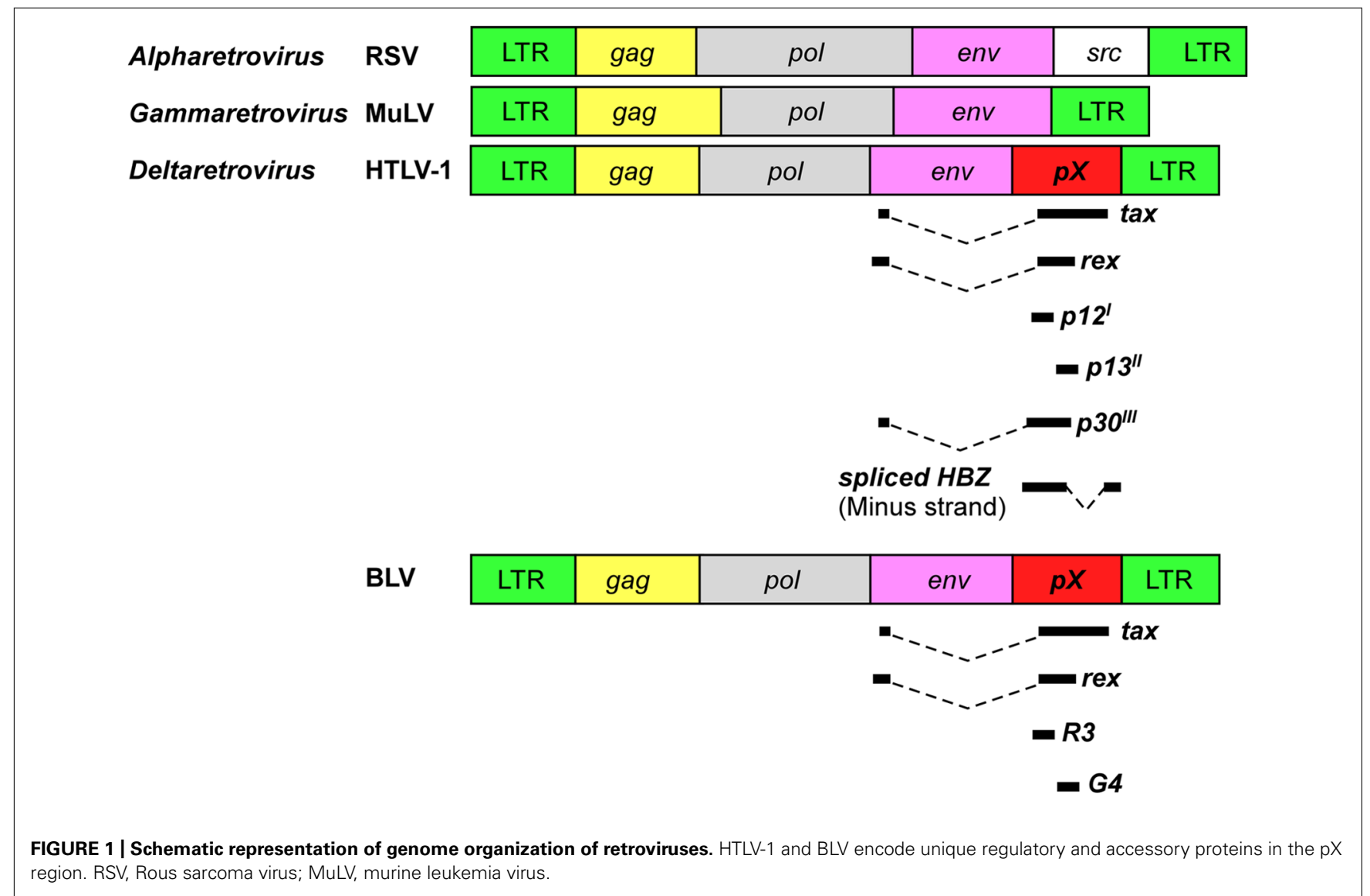

et al., 1990). Because their structure and properties differ from any other class of retroviruses, BLV and HTLV-1 viruses were classified into a new group of retroviruses (Gillet et al., 2007). In both viruses the regulatory proteins Tax and Rex are encoded in the $\mathrm{pX}$ region. The $\mathrm{R} 3$ and $\mathrm{G} 4$ proteins are encoded in the $\mathrm{BLV} \mathrm{pX}$ region, while $\mathrm{p} 12^{\mathrm{I}}, \mathrm{p} 13^{\mathrm{II}}$, and $\mathrm{p} 30^{\mathrm{II}}$ are encoded in the HTLV- $1 \mathrm{pX}$ region (Sagata et al., 1984b; Franchini et al., 2003; Figure 1). Interestingly, the HTLV-1 genome codes for HBZ, a unique gene encoded by the minus strand chain (Gaudray et al., 2002; Figure 1). The major functions of the viral proteins encoded in the BLV and HTLV-1 pX regions are summarized in Table 1 . The Tax protein has been extensively studied, and it is believed to play a critical role in leukemogenesis induced by BLV and HTLV-1 (Katoh et al., 1989; Tanaka et al., 1990; Willems et al., 1990). The Rex protein is responsible for nuclear export of viral RNA and promotes cytoplasmic accumulation and translation of viral messenger mRNA in BLV- and HTLV-1-infected cells (Felber et al., 1989). BLV R3 and G4 proteins contribute to the maintenance of high viral load (Willems et al., 1994; Florins et al., 2007). The G4 protein is particularly relevant to leukemogenesis, since it can immortalize primary rat embryo fibroblasts (REFs; Lefebvre et al., 2002). HTLV- 1 p $12^{\mathrm{I}}$ is similar to the R3 protein, in that it contributes to the maintenance of infectivity (Collins et al., 1998), and both proteins are located in the nucleus and cellular membranes (Gillet et al., 2007). On the other hand, HTLV-1 $13^{\mathrm{II}}$ protein resembles the G4 protein, since both proteins bind to farnesyl pyrophosphate synthetase, which farnesylates Ras (Lefebvre et al., 2002), and the $\mathrm{p} 13^{\mathrm{II}}$ protein promotes Ras-dependent apoptosis (Hiraragi et al., 2005). HTLV-1 p30 ${ }^{\mathrm{II}}$ protein regulates gene transcription through its interaction with the cAMP responsive element (CRE) binding protein (CREB)/p300 (Zhang et al., 2001). The HBZ protein plays a critical role in the leukemogenesis of HTLV-1, and HBZ knockdown inhibits the proliferation of ATL cells (Satou et al., 2006). However, since the BLV genome does not code for HBZ, it is assumed that the Tax protein plays a central role in the leukemogenesis of BLV.

The infection route of BLV and HTLV is by horizontal and vertical transmission. BLV is transmitted via direct contact (Kono et al., 1983), milk, and insect bites (Ferrer and Piper, 1978), while HTLV-1 is transmitted via milk and sexual intercourse (Bangham, 2003). Moreover, the artificial transmission of BLV is caused by iatrogenic procedures such as dehorning, ear tattooing, and reuse of needles (Hopkins and DiGiacomo, 1997), whereas the artificial transmission of HTLV-1 is caused by blood transfusion and needle sharing among drug abusers (Robert-Guroff et al., 1986). Since cell contact is required for the efficient transmission of both BLV and HTLV-1, cell-free infection by these viruses is believed to be very inefficient, most probably due to virion instability (Voneche et al., 1992; Johnston et al., 1996; Igakura et al., 2003).

As shown in Figure 2, an infection with BLV is characterized by three progressive stages of disease, including an asymptomatic 
Table 1 | Viral proteins are encoded in BLV and HTLV-1 pX regions.

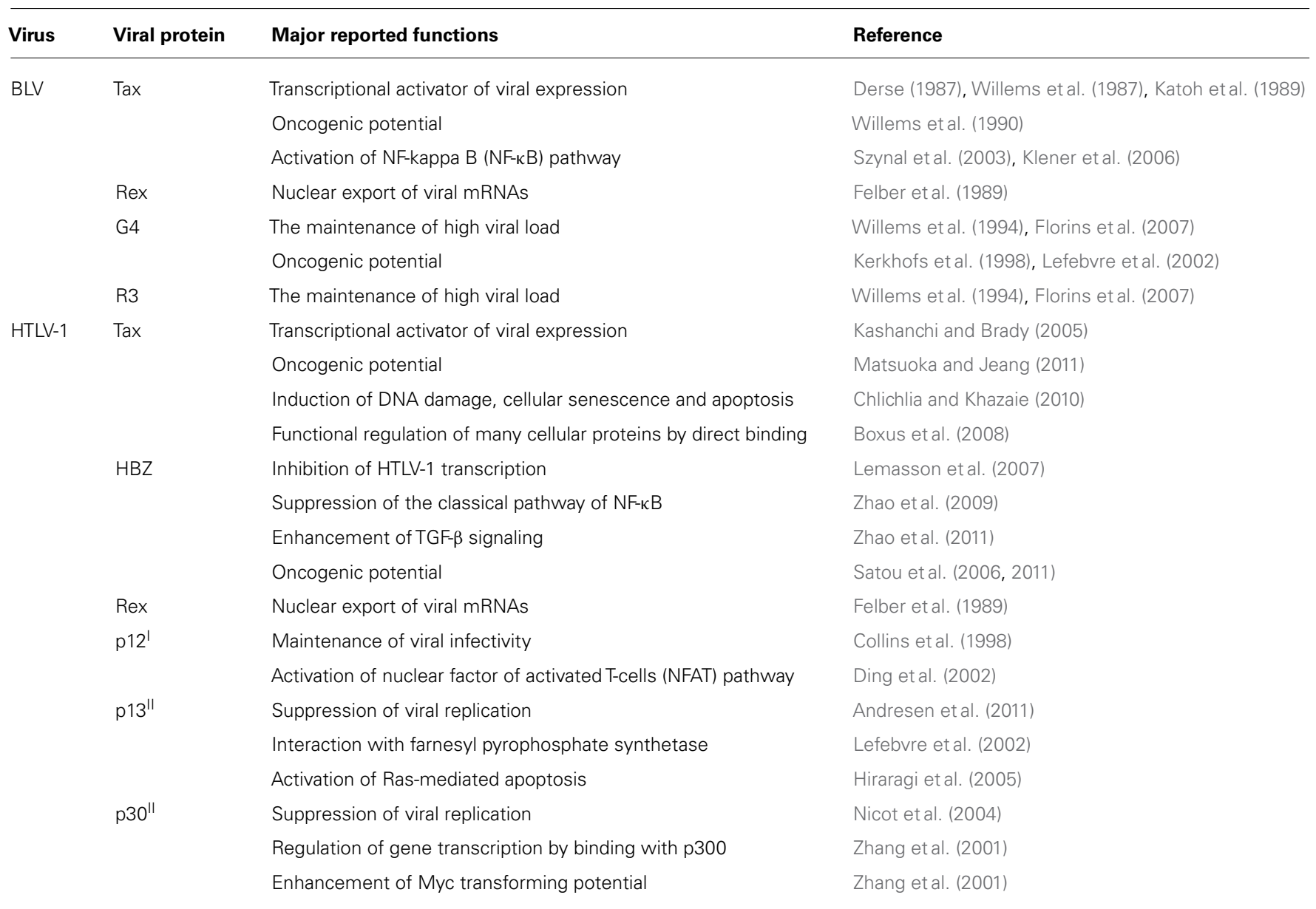

stage, PL, and lymphoma. Most BLV-infected cattle are asymptomatic, but approximately one-third of them suffer from PL characterized by a permanent and relatively stable increase in the number of B-lymphocytes in the peripheral blood. PL is considered to be a benign form of the disease resulting from the accumulation of untransformed B-lymphocytes. Finally, 1-5\% of BLV-infected cattle develop B-lymphoma in various lymph nodes after a long latency period (Schwartz and Levy, 1994; Florins et al., 2008). Although BLV can also infect CD $4^{+}$T-cells, CD8 ${ }^{+}$T-cells, $\gamma / \delta$ T-cells, monocytes, and granulocytes in cattle (Williams et al., 1988; Stott et al., 1991; Schwartz et al., 1994; Mirsky et al., 1996; Wu et al., 1996; Panei et al., 2013), a large number of the tumor cells are derived from $\mathrm{CD}^{+} \mathrm{IgM}^{+}$B-cell subpopulations (Schwartz and Levy, 1994). Interestingly, the full-length BLV proviral genome is maintained in each animal throughout the course of the disease (Tajima etal., 1998a). In addition, previous studies have shown that both large and small deletions of proviral genomes may be very rare events in BLV-infected cattle. Thus, the proviral loads were significantly increased at the PL stage compared with the aleukemic stage and were further increased at the lymphoma stage (Jimba et al., 2010, 2012; Figure 2B). These findings clearly demonstrated that the BLV proviral copy number increases with increasing severity of the disease. On the other hand, unlike BLV,
HTLV-1 is associated with ATL and with the chronic neurological disorder, HAM/TSP, and induces not only a malignant tumor but also an inflammatory disease (Gessain et al., 1985; Osame et al., 1986). Although the pathogenesis of HTLV-1 is slightly different from BLV, HTLV-1, like BLV, can infect many cells in addition to T-cells, including B-cells and monocytes (Koyanagi et al., 1993; Schwartz and Levy, 1994). In contrast to BLV, defective HTLV-1 proviral genomes have been found in more than half of all examined patients with ATL (Konishi et al., 1984; Korber et al., 1991; Ohshima et al., 1991; Tsukasaki et al., 1997).

\section{MECHANISM OF LEUKEMOGENESIS BY BLV}

Animal retroviruses, which belong to the Alpharetrovirus and Gammaretrovirus genera, induce tumors by one of two mechanisms: either by activation of the "viral oncogene" or by "insertional activation" of a cellular gene such as a proto-oncogene (Weiss et al., 1985; Figure 1). By contrast, BLV lacks a known oncogene (Sagata et al., 1984a,b) and does not integrate into preferred sites in their host cell genomes, which related to the disruption of the host gene but not to the suppression of viral gene expression (Murakami et al., 2011b).

Most studies of BLV-induced leukemogenesis have focused on the Tax protein because it is believed to be a potent transcriptional 
A

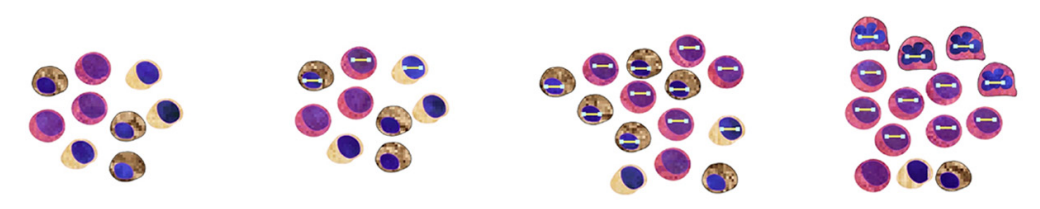

Asymtomatic PL Lymphoma

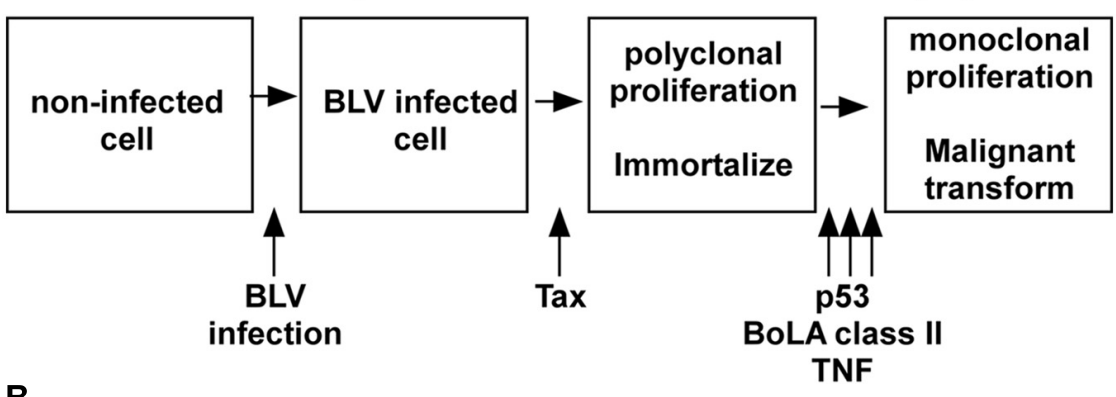

B

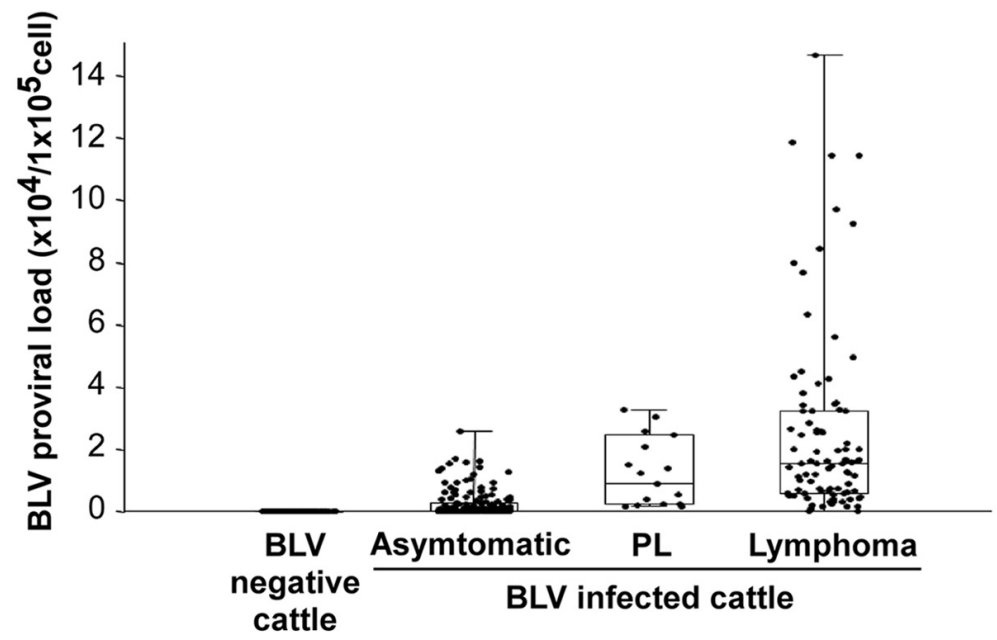

FIGURE 2 | BLV-induced leukemogenesis is a multistep process. (A) An infection with BLV is characterized by three progressive stages of disease: asymptomatic stage, persistent lymphocytosis (PL), and lymphoma. BLV infects to cells non-specifically. Among them, BLV Tax protein immortalizes a part of BLV-infected cells, probably only $\mathrm{CD}^{+} \operatorname{lgM}^{+}$B-cells, and induces polyclonal proliferation of the cells. However, the Tax protein does not have the ability to transform the cells. For lymphoma to develop, a malignant transformation needs to occur with the help of host factors, such as p53 mutation, TNF- $\alpha$ activities or bovine leukocyte antigen (BoLA) class II phosphorylation. (B) The provirus load increases with disease progression. activator of viral gene expression. In addition to its function as a transcriptional activator, Tax induces immortalization of primary REFs (Willems et al., 1990, 1998). Furthermore, Tax cooperates with the Harvey rat sarcoma viral oncoprotein (Ha-ras) for the induction of full transformation of primary REF (Willems et al., 1990). Importantly, the Tax transformed cells induce tumors in nude mice. The ability of the Tax protein to induce immortalization may be the first step in the BLV-mediated transformation process. Moreover, after the infection of cattle and during the latency period, the expression of BLV becomes blocked at the transcriptional level (Kettmann et al., 1982; Lagarias and Radke, 1989). Such repression appears to be very important for the escape of BLV from the host's immunosurveillance system, and later only a certain small proportion of infected animals rapidly develop a terminal disease (Gillet et al., 2007). Indeed, transcription of the
BLV genome in fresh tumor cells or in fresh peripheral blood mononuclear cells (PBMCs) from infected individuals is almost undetectable by conventional techniques (Kettmann et al., 1982; Tajima et al., 2003b; Tajima and Aida, 2005). In situ hybridization has revealed the expression of viral RNA at low levels in many cells, and at a high level in only a few cells within PBMCs freshly isolated from BLV-infected asymptomatic animals (Lagarias and Radke, 1989). Thus, BLV infection is probably not sufficient for leukemogenesis and some additional events such as gene mutations might be involved in the leukemogenic process (Figure 2A). Taken together, Tax may induce immortalization of only $\mathrm{CD}^{+}$ $\mathrm{IgM}^{+} \mathrm{B}$-cells among BLV-infected B-cells, CD4 ${ }^{+}$T-cells, $\mathrm{CD}^{+}$ T-cells, $\gamma / \delta$ T-cells, monocytes, and granulocytes in cattle, thereby conferring a selective transformation advantage to the infected $\mathrm{CD}^{+}{ }^{+} \operatorname{IgM}^{+}$B-cells by a second event. 
A mutation in the p53 tumor suppressor gene is one of several genetic changes known to be involved in the development of lymphoma (Figure 2A). The protein encoded by the p53 tumor suppressor gene plays a critical role in transducing a signal from the damaged DNA to genes that control cell cycle and apoptosis. Approximately half of the solid tumors induced by BLV in cattle (Dequiedt et al., 1995; Ishiguro et al., 1997; Zhuang et al., 1997; Tajima et al., 1998b) and three of four bovine B-cell lymphoma lines (Komori et al., 1996) were shown to harbor missense mutations in p53. By contrast, very few mutations were found in B-cells from cows with PL and none of the uninfected cattle harbored a mutated p53 gene. These observations indicate that p53 mutations frequently occur at the final stage of lymphoma in cattle. A previous study of the molecular mechanism of mutations at codons 206, 207, 241, and 242, which were identified in lymphoma, showed that these mutations may potentially alter the wild-type function of the bovine p53 protein, including the conformation and transactivator and growth suppressor activities, and then cause lymphoma (Tajima et al., 1998b). These four mutations were clearly divided into two functionally distinct groups: (i) the mutant forms with substitutions at codons 241 and 242, which were mapped within an evolutionarily conserved region and corresponded to the human "hot-spot" mutations, and had completely lost the capacity for transactivation and growth suppression while gaining transdominant repression activity in p53-null SAOS-2 cells; and (ii) the mutations at codons 206 and 207, which were located outside the evolutionarily conserved regions and partially retained the capacity for transactivation and growth suppression. Collectively, these naturally occurring mutations may potentially alter the wild-type function, and in addition, out of the four missense mutations, at least two mutations may be sufficient to cause lymphoma. However, since the other two mutations may be insufficient to induce lymphoma, it is possible that other cancerrelated genes may contribute to lymphoma in concert with the p53 mutations.

A major factor involved in the clinical progression of BLV-infected animals is the bovine leukocyte antigen (BoLA; Figure 2A), which plays a crucial role in determining immune responsiveness (Lewin and Bernoco, 1986; Lewin et al., 1988; Zanotti et al., 1996; Takeshima and Aida, 2006). Several studies have shown that genetic variations in $B o L A-D R B 3$, which is a functionally important and the most polymorphic BoLA class II locus in cattle, influence resistance and susceptibility to a wide variety of infectious diseases, including lymphoma (Aida, 2001) and PL (Xu et al., 1993; Sulimova et al., 1995; Starkenburg et al., 1997; Juliarena et al., 2008), and affect BLV proviral load (Miyasaka et al., 2013). For example, the presence of the amino acids GluArg (ER) at positions 70-71 of the BoLA-DR $\beta$ chain was associated with resistance to PL in BLV-infected cattle (Xu et al., 1993). Furthermore, the BoLA-DRB3 alleles encoding Glu, Arg, and Val at positions 74,77 , and 78 , respectively, of the BoLA-DR $\beta$ chain might be associated with resistance to tumor development (Aida, 2001). In a related study, Nagaoka et al. (1999) and Konnai et al. (2003) found that the ovine leukocyte antigen (OLA)-DRB1 alleles encoding the Arg-Lys (RK) and the Ser-Arg (SR) motifs at positions $70-71$ of the OLA-DR $\beta$ chain are associated with resistance
(RK motif) and susceptibility (SR motif) to the development of lymphoma after experimental infection of sheep with BLV. The sheep with alleles encoding the RK motif produced neutralizing antibodies against BLV and interferon- $\gamma$, eliminated BLV completely, and did not develop lymphoma (Konnai etal., 2003). The susceptibility to the monoclonal expansion of BLV-infected B-lymphocytes is thus associated with specific alleles of BoLA system.

A polymorphism in the promoter region of the tumor necrosis factor (TNF)- $\alpha$ gene is one of several genetic changes involved in the development of lymphoma (Figure 2A). A previous study found that, in sheep experimentally infected with BLV, the frequency of the TNF- $\alpha-824 \mathrm{G}$ allele, which has been associated with low transcription activity of the promoter/predicted enhancer region of the bovine TNF- $\alpha$ gene, was higher in animals with lymphoma than in asymptomatic carrier animals. In addition, a tendency was observed for increased BLV-provirus load in cattle homozygous for the TNF- $\alpha-824 \mathrm{G} / \mathrm{G}$ allele compared to cattle homozygous for the TNF- $\alpha-824 \mathrm{~A} / \mathrm{A}$ or TNF- $\alpha-824 \mathrm{~A} / \mathrm{G}$ alleles. These data suggest that the observed polymorphism in the promoter region of the TNF- $\alpha$ gene could at least in part contribute to the progression of lymphoma in BLV infection (Konnai et al., 2006).

The BLV studies have also focused on understanding the process of signal transduction such as B-cell receptor (BCR) signaling (Alber et al., 1993), since many signal transduction factors have been implicated in leukemogenesis of B-cells in humans (Murakami et al., 2011a). For example, the immunoreceptor tyrosine-based activation (ITAM) motifs present in the transmembrane gp30 proteins of the BLV envelope are important for the incorporation of envelope proteins into the virion (Inabe etal., 1999) and are required for infectivity in vivo (Willems et al., 1995). In addition to the viral signaling motif, the spleen tyrosine kinase (Syk) mRNA expression was significantly increased in PL samples, whereas it was decreased in tumor samples, suggesting that Syk mRNA expression dynamics is closely related to the progression of BLV-induced disease (Murakami et al., 2011a).

\section{BLV Tax FUNCTION}

As mentioned above, the Tax gene is a key contributor to the oncogenic potential, as well as a key protein involved in the replication of the virus. Table 1 summarizes the functions of the Tax protein. The Tax open reading frame is mainly encoded in the $\mathrm{pX}$ region, and its translation occurs upstream of the pol stop codon. The Tax protein is modified by phosphorylation of two serine residues and is detected as a $34-38 \mathrm{kDa}$ product (Chen et al., 1989; Willems et al., 1998). In addition, the Tax protein has T- and B-cell epitopes corresponding to regions 110-130/131150 and 261-280, respectively (Sakakibara et al., 1998). One of the best characterized functions of Tax is the activation of viral transcription. The Tax protein acts on a triplicate $21 \mathrm{bp}$ enhancer motif known as the Tax-responsive element (TxRE) in the U3 region of the $5^{\prime} \mathrm{LTR}$, and it stimulates transactivation of the viral genome (Derse, 1987; Willems et al., 1987; Katoh et al., 1989). The TxRE consists of a cyclic AMP-response element (CRE)-like sequence, and it has been suggested that Tax binds to this element 
indirectly through cellular factors, such as the members of the CREB/activating transcription factor (ATF) family of basic leucine zipper proteins that have been shown to bind to the CRE-like sequence (Adam et al., 1994, 1996; Boros et al., 1995). Furthermore, the Tax protein modulates the expression of cellular genes that are involved in the regulation of cell growth (Tajima and Aida, 2002). In addition to its function in the regulation of cellular and viral transcription, the Tax protein can induce immortalization of primary REF and cooperates with Ha-Ras oncogene to fully transform the primary cells (Willems et al., 1990). On the other hand, the transactivation and transformation of Tax may be independently induced by each mechanism, since phosphorylation of Tax is required for its transformation but not for its activation (Willems et al., 1998). Moreover, the expression of Tax in primary ovine B-cells, which depends on CD154 and interleukin-4, affects B-cell proliferation, cell cycle phase distribution, and survival, leading to cytokine-independent growth (Szynal et al., 2003). This immortalization process is also associated with increased B cell leukemia/lymphoma 2 (Bcl-2) protein levels, nuclear factor kappa B (NF-кB) accumulation, and a series of intracellular pathways that remain to be characterized (Klener et al., 2006). In addition, Tax inhibits base-excision DNA repair of oxidative damage, thereby potentially increasing the accumulation of ambient mutations in cellular DNA (Philpott and Buehring, 1999).

\section{NEGATIVE REGULATION OF BLV Tax BY THE REGION BETWEEN RESIDUES 240-265}

Our studies (Tajima and Aida, 2000) demonstrated new functions of the region between amino acids 240 and 265 of BLV Tax. As shown in Figure 3, a series of mutants with at least one amino acid substitution between amino acids 240 and 265 of BLV Tax were identified, including TaxD247G and TaxS240P, which exhibit an enhanced ability to stimulate and reduce viral LTR-directed transcription respectively, compared to the wild-type protein (Tajima and Aida, 2000). Transient expression analysis revealed that the TaxD247G mutant increased the production of viral protein and particles from a defective recombinant proviral BLV clone to a greater extent than the wild-type Tax (TaxWT). Conversely, the TaxS240P mutant was unable to induce the release of viral particles. The microarray data in human HeLa cells and its validation of differentially expressed genes at the RNA and protein levels in bovine 23CLN cells revealed several alterations in genes involved in many cellular functions such as transcription, signal transduction, cell growth, apoptosis, and the immune response (Arainga et al., 2012). In both of human HeLa cells and bovine 23CLN cells, the TaxD247G mutant induced higher gene expression compared with TaxWT and TaxS240P and many of these genes were expressed at the lowest level in the TaxS240P-transfected cells. In particular, our results showed that Tax activates the proteins which are involved in activator protein 1 (AP-1) signaling pathway [FBJ osteosarcoma

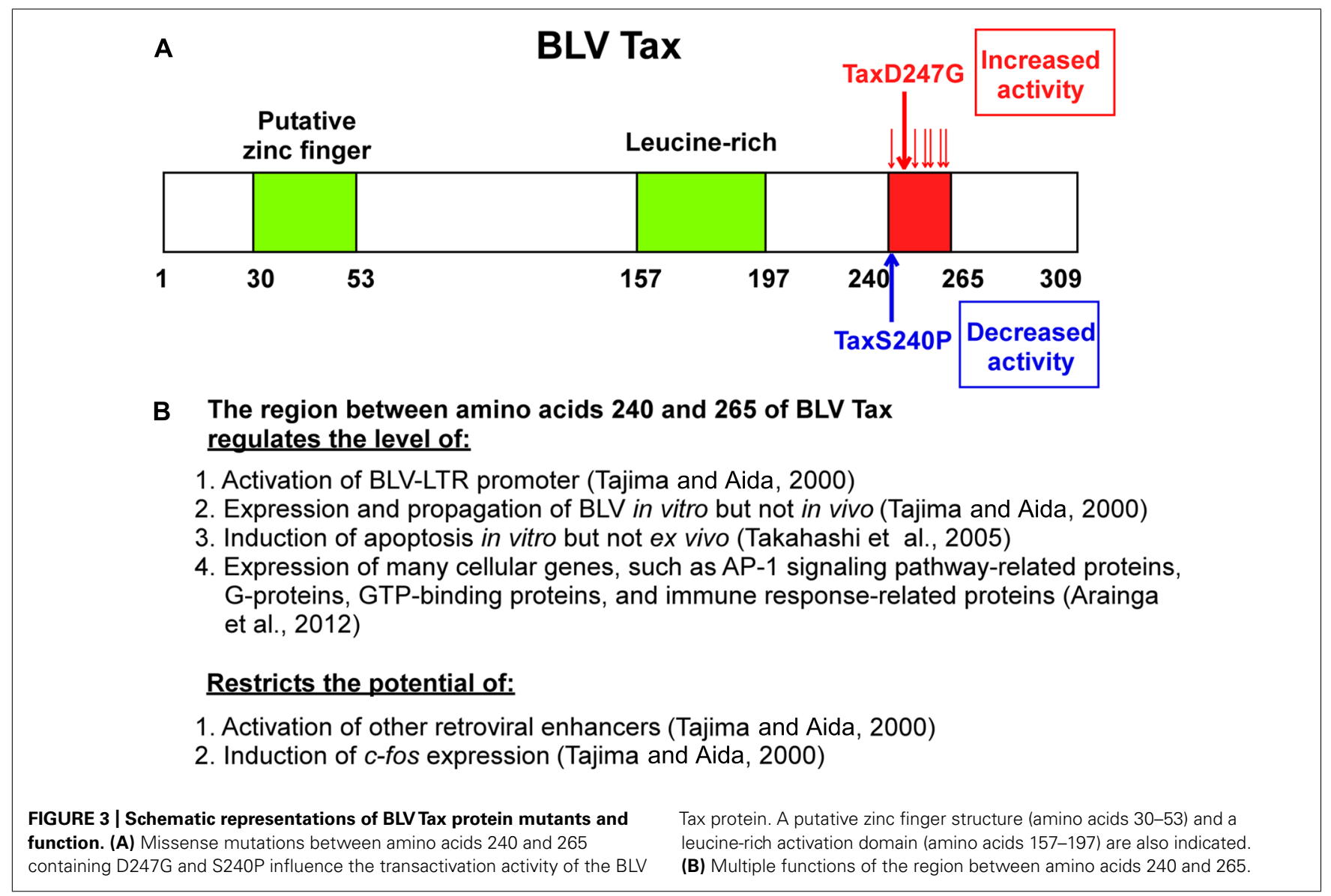


oncogene (FOS), jun proto-oncogene (JUN), etc.] via interactions with other transcriptional pathways (G-protein, GTP-binding proteins, etc.). Likewise, the TaxD247G mutant induced apoptosis in transfected cells more effectively than the TaxWT (Takahashi et al., 2005). These results suggest that the region between amino acids 240 and 265 of the Tax protein might act as a negative regulatory domain, and missense mutations in this region might lead to enhanced transactivation activity of Tax, expression of many cellular genes and induction of apoptosis. Our results raise the possibility that the target sequence specificity of retroviral enhancers of Tax might be limited by this region because TaxD247G, but not TaxS240P, was found to activate other retroviral enhancers such as HTLV-1, HIV-1, and mouse mammary tumor virus (MMTV) and Moloney murine leukemia virus (M-MuLV), and $c$-fos, which are not activated by TaxWT (Tajima and Aida, 2000; Figure 3B). The microarray data also raised the possibility that BLV Tax regulates the innate immune response (Figure 3B): the largest group of downregulated genes was related to the immune response, and the majority of these genes belonged to the interferon family of antiviral factors, such as interferon-induced protein with tetratricopeptide repeats 1 (IFIT1; Arainga et al., 2012). Interferons are major components of the innate immune system, and are recognized for their antiviral function in addition to their antiproliferative and immunomodulatory effects on cells ( $\mathrm{Hu}$ et al., 1993). It is likely that BLV Tax downregulates the innate immune response, thereby increasing the production of viral protein.

An infectious molecular clone of BLV encoding the TaxD247G was examined for the viral expression and propagation, as well as for the induction of apoptosis in a sheep model (Tajima et al., 2003a; Takahashi et al., 2004, 2005). Interestingly, the infectious molecular clone of BLV encoding the TaxD247G produced more viral particles and was transmitted at an elevated rate in vitro, but with no significant differences in the proviral load and the expression of viral RNA between sheep experimentally injected with BLVs encoding the TaxWT or the mutant TaxD247G proteins (Tajima et al., 2003a). These findings suggest the presence of a dominant host defense mechanism regulating BLV-LTR-directed transcription by Tax that may play an important role in viral silencing in vivo (Figure 4). Likewise, although the transient

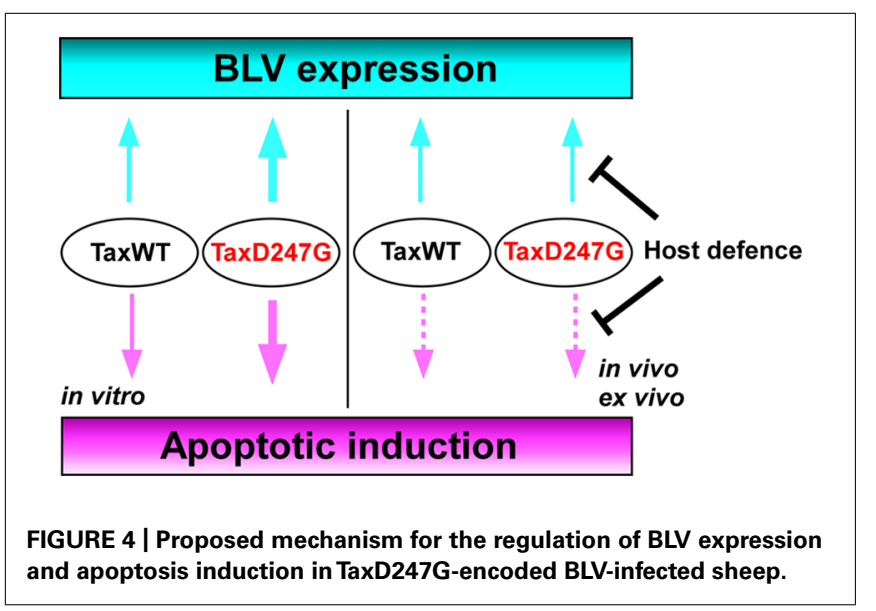

expression of TaxD247G induced apoptosis in transfected cells in vitro more effectively than TaxWT, higher level of protection against apoptosis was observed in PBMCs isolated from sheep infected with TaxD247G-encoded BLV compared to TaxWTencoded BLV (Takahashi et al., 2005; Figure 4). These findings demonstrate that TaxD247G has an increased potential to induce apoptosis, which could be beneficial for BLV propagation like other viruses (Wurzer et al., 2003; Richard and Tulasne, 2012). One possible explanation for our results might be that TaxD247G-induced apoptosis is modulated by a dominant mechanism ex vivo, so the function might be suppressed.

\section{CONCLUSION}

BLV is the etiologic agent of EBL, which is the most common neoplastic disease in cattle. It infects cattle worldwide, thereby imposing a severe economic burden on the dairy cattle industry. In this review, we evaluated existing information on the mechanism of BLV-induced leukemogenesis. We propose that, since BLV Tax induces immortalization of only $\mathrm{CD}^{+} \mathrm{IgM}^{+} \mathrm{B}$-cells within BLV-infected B-cells, CD4 ${ }^{+}$T-cells, CD8 ${ }^{+}$T-cells, $\gamma / \delta$ T-cells, monocytes, and granulocytes in cattle, it may confer a selective transformation advantage to the infected $\mathrm{CD}^{+} \mathrm{IgM}^{+}$ B-cells by a second event, such as $\mathrm{p} 53$ mutation, polymorphisms of BoLA, or the promoter region of the TNF- $\alpha$ gene. We also propose new functions of the region between amino acids 240 and 265 of BLV Tax (Figure 3). Namely, the transactivation activity and target sequence specificity of BLV Tax might be limited or negatively regulated by this region. The most interesting point regarding the ability of TaxD247G to enhance BLV expression and apoptotic induction in vitro is that it might be suppressed in vivo or ex vivo. Thus, we hypothesize that there could be dominant mechanisms controlling the functions of TaxD247G ex vivo and in vivo, as shown in Figure 4. For HTLV-1, it has been reported that $\mathrm{CD}^{+}$cell-mediated cytotoxic T-lymphocytes (CTLs) target Tax-expressing cells, thereby reducing the number of infected cells (Hanon et al., 2000). Likewise, BLV-infected cells expressing Tax may be exposed to the host defense system, and BLV may evolve in a manner that promotes the shielding of their potential abilities. Therefore, a strong transactivation activity of BLV Tax might not be advantageous for the propagation of BLV in vivo. Taken together, the findings discussed in this review suggest that there might be a dominant mechanism involved in the induction of apoptosis and expression of HTLV-1 in vivo. To address our hypothesis, it seems necessary to evaluate whether possible host responses against BLV infection, such as the induction of CTLs, genetic, and epigenetic alterations in apoptosis-regulatory genes, and DNA and chromatin modifications of BLV promoter for the suppression of viral expression, could be enhanced in animals infected with TaxD247G-encoded BLV. Thus, future investigations of the relationship between apoptosis and viral expression using BLV containing the mutant D247G Tax as a model will broaden our understanding of the replication and propagation of HTLV-1, and leukemia progression.

\section{ACKNOWLEDGMENTS}

The studies on BLV were supported by Grants-in-Aid for Scientific Research (A, B, and C) from the Japan Society for the Promotion of 
Science (JSPS), and by a grant from the Program for the Promotion of Basic and Applied Research for Innovations in Bio-oriented Industry.

\section{REFERENCES}

Adam, E., Kerkhofs, P., Mammerickx, M., Burny, A., Kettmann, R., and Willems, L. (1996). The CREB, ATF-1, and ATF-2 transcription factors from bovine leukemia virus-infected B lymphocytes activate viral expression. J. Virol. 70, 1990-1999.

Adam, E., Kerkhofs, P., Mammerickx, M., Kettmann, R., Burny, A., Droogmans, L., et al. (1994). Involvement of the cyclic AMP-responsive element binding protein in bovine leukemia virus expression in vivo. J. Virol. 68, 5845-5853.

Aida, Y. (2001). Influence of host genetic differences on leukemogenesis induced by bovine leukemia virus. AIDS Res. Hum. Retroviruses 17, S12.

Aida, Y., Miyasaka, M., Okada, K., Onuma, M., Kogure, S., Suzuki, M., et al. (1989). Further phenotypic characterization of target cells for bovine leukemia virus experimental infection in sheep. Am. J. Vet. Res. 50, 1946-1951.

Aida, Y., Okada, K., and Amanuma, H. (1993). Phenotype and ontogeny of cells carrying a tumor-associated antigen that is expressed on bovine leukemia virusinduced lymphosarcoma. Cancer Res. 53, 429-437.

Alber, G., Kim, K. M., Weiser, P., Riesterer, C., Carsetti, R., and Reth, M. (1993). Molecular mimicry of the antigen receptor signalling motif by transmembrane proteins of the Epstein-Barr virus and the bovine leukaemia virus. Curr. Biol. 3, 333-339. doi: 10.1016/0960-9822(93)90196-U

Altanerova, V., Ban, J., Kettmann, R., and Altaner, C. (1990). Induction of leukemia in chicken by bovine leukemia virus due to insertional mutagenesis. Arch. Geschwulstforsch. 60, 89-96.

Altanerova, V., Portetelle, D., Kettmann, R., and Altaner, C. (1989). Infection of rats with bovine leukaemia virus: establishment of a virus-producing rat cell line. $J$. Gen. Virol. 70(Pt 7), 1929-1932. doi: 10.1099/0022-1317-70-7-1929

Andresen, V., Pise-Masison, C. A., Sinha-Datta, U., Bellon, M., Valeri, V., Washington Parks, R., et al. (2011). Suppression of HTLV-1 replication by Tax-mediated rerouting of the p13 viral protein to nuclear speckles. Blood 118, 1549-1559. doi: 10.1182/blood-2010-06-293340

Arainga, M., Takeda, E., and Aida, Y. (2012). Identification of bovine leukemia virus tax function associated with host cell transcription, signaling, stress response and immune response pathway by microarray-based gene expression analysis. BMC Genomics 13:121. doi: 10.1186/1471-2164-13-121

Bangham, C. R. (2003). Human T-lymphotropic virus type 1 (HTLV-1): persistence and immune control. Int. J. Hematol. 78, 297-303. doi: 10.1007/BF02983553

Boros, I. M., Tie, F., and Giam, C. Z. (1995). Interaction of bovine leukemia virus transactivator Tax with bZip proteins. Virology 214, 207-214. doi: 10.1006/viro.1995.9939

Boxus, M., Twizere, J. C., Legros, S., Dewulf, J. F., Kettmann, R., and Willems, L. (2008). The HTLV-1 Tax interactome. Retrovirology 5, 76. doi: 10.1186/1742 4690-5-76

Burny, A., Bex, F., Bruck, C., Cleuter, Y., Dekegel, D., Ghysdael, J., et al. (1979). Biochemical and epidemiological studies on bovine leukemia virus (BLV). Haematol. Blood Transfus. 23, 445-452.

Chen, G., Willems, L., Portetelle, D., Willard-Gallo, K. E., Burny, A., Gheysen, D., et al. (1989). Synthesis of functional bovine leukemia virus (BLV) p34tax protein by recombinant baculoviruses. Virology 173, 343-347. doi: 10.1016/00426822(89)90254-7

Chlichlia, K., and Khazaie, K. (2010). HTLV-1 Tax: linking transformation, DNA damage and apoptotic T-cell death. Chem. Biol. Interact. 188, 359-365. doi: 10.1016/j.cbi.2010.06.005

Collins, N. D., Newbound, G. C., Albrecht, B., Beard, J. L., Ratner, L., and Lairmore M. D. (1998). Selective ablation of human T-cell lymphotropic virus type 1 p12I reduces viral infectivity in vivo. Blood 91, 4701-4707.

Dequiedt, F., Kettmann, R., Burny, A., and Willems, L. (1995). Mutations in the p53 tumor-suppressor gene are frequently associated with bovine leukemia virusinduced leukemogenesis in cattle but not in sheep. Virology 209, 676-683. doi: $10.1006 /$ viro. 1995.1303

Derse, D. (1987). Bovine leukemia virus transcription is controlled by a virusencoded trans-acting factor and by cis-acting response elements. J. Virol. 61, 2462-2471.

Ding, W., Albrecht, B., Kelley, R. E., Muthusamy, N., Kim, S. J., Altschuld, R. A., et al. (2002). Human T-cell lymphotropic virus type 1 p12(I) expression increases cytoplasmic calcium to enhance the activation of nuclear factor of activated $\mathrm{T}$ cells. J. Virol. 76, 10374-10382. doi: 10.1128/JVI.76.20.10374-10382.2002

Djilali, S., and Parodi, A. L. (1989). The BLV-induced leukemia-lymphosarcoma complex in sheep. Vet. Immunol. Immunopathol. 22, 233-244. doi: 10.1016/01652427(89)90010-X

Felber, B. K., Derse, D., Athanassopoulos, A., Campbell, M., and Pavlakis, G. N. (1989). Cross-activation of the Rex proteins of HTLV-I and BLV and of the Rev protein of HIV-1 and nonreciprocal interactions with their RNA responsive elements. New Biol. 1, 318-328.

Ferrer, J. F., Marshak, R. R., Abt, D. A., and Kenyon, S. J. (1978). Persistent lymphocytosis in cattle: its cause, nature and relation to lymphosarcoma. Ann. Rech. Vet. 9, 851-857.

Ferrer, J. F., and Piper, C. E. (1978). An evaluation of the role of milk in the natural transmission of BLV. Ann. Rech. Vet. 9, 803-807.

Florins, A., Boxus, M., Vandermeers, F., Verlaeten, O., Bouzar, A. B., Defoiche, J., et al. (2008). Emphasis on cell turnover in two hosts infected by bovine leukemia virus: a rationale for host susceptibility to disease. Vet. Immunol. Immunopathol. 125, 1-7. doi: 10.1016/j.vetimm.2008.04.007

Florins, A., Gillet, N., Boxus, M., Kerkhofs, P., Kettmann, R., and Willems, L. (2007). Even attenuated bovine leukemia virus proviruses can be pathogenic in sheep. J. Virol. 81, 10195-10200. doi: 10.1128/JVI.01058-07

Franchini, G., Fukumoto, R., and Fullen, J. R. (2003). T-cell control by human T-cell leukemia/lymphoma virus type 1. Int. J. Hematol. 78, 280-296. doi: 10.1007/BF02983552

Gaudray, G., Gachon, F., Basbous, J., Biard-Piechaczyk, M., Devaux, C., and Mesnard, J. M. (2002). The complementary strand of the human T-cell leukemia virus type 1 RNA genome encodes a bZIP transcription factor that down-regulates viral transcription. J. Virol. 76, 12813-12822. doi: 10.1128/JVI.76.24.1281312822.2002

Gessain, A., Barin, F., Vernant, J. C., Gout, O., Maurs, L., Calender, A., et al. (1985). Antibodies to human T-lymphotropic virus type-I in patients with tropical spastic paraparesis. Lancet 2, 407-410. doi: 10.1016/S0140-6736(85)92734-5

Gillet, N., Florins, A., Boxus, M., Burteau, C., Nigro, A., Vandermeers, F., et al. (2007). Mechanisms of leukemogenesis induced by bovine leukemia virus: prospects for novel anti-retroviral therapies in human. Retrovirology 4, 18. doi: 10.1186/1742-4690-4-18

Grassmann, R., Dengler, C., Muller-Fleckenstein, I., Fleckenstein, B., Mcguire, K., Dokhelar, M. C., et al. (1989). Transformation to continuous growth of primary human $\mathrm{T}$ lymphocytes by human T-cell leukemia virus type I X-region genes transduced by a Herpesvirus saimiri vector. Proc. Natl. Acad. Sci. U.S.A. 86, 3351-3355. doi: 10.1073/pnas.86.9.3351

Graves, D. C., and Ferrer, J. F. (1976). In vitro transmission and propagation of the bovine leukemia virus in monolayer cell cultures. Cancer Res. 36, 4152-4159.

Hanon, E., Hall, S., Taylor, G. P., Saito, M., Davis, R., Tanaka, Y., et al. (2000). Abundant tax protein expression in CD4+ T cells infected with human T-cell lymphotropic virus type I (HTLV-I) is prevented by cytotoxic T lymphocytes. Blood 95, 1386-1392.

Hiraragi, H., Michael, B., Nair, A., Silic-Benussi, M., Ciminale, V., and Lairmore, M. (2005). Human T-lymphotropic virus type 1 mitochondrion-localizing protein p13II sensitizes Jurkat $\mathrm{T}$ cells to Rasmediated apoptosis. J. Virol. 79, 9449-9457. doi: 10.1128/JVI.79.15.9449-9457. 2005

Hopkins, S. G., and DiGiacomo, R. F. (1997). Natural transmission of bovine leukemia virus in dairy and beef cattle. Vet. Clin. North Am. Food Anim. Pract. 13, 107-128.

Hu, R., Gan, Y., Liu, J., Miller, D., and Zoon, K. C. (1993). Evidence for multiple binding sites for several components of human lymphoblastoid interferon-alpha. J. Biol. Chem. 268, 12591-12595.

Igakura, T., Stinchcombe, J. C., Goon, P. K., Taylor, G. P., Weber, J. N., Griffiths, G. M., et al. (2003). Spread of HTLV-I between lymphocytes by virus-induced polarization of the cytoskeleton. Science 299, 1713-1716. doi: 10.1126/science. 1080115

Inabe, K., Nishizawa, M., Tajima, S., Ikuta, K., and Aida, Y. (1999). The YXXL sequences of a transmembrane protein of bovine leukemia virus are required for viral entry and incorporation of viral envelope protein into virions. J. Virol. 73, 1293-1301.

Ishiguro, N., Furuoka, H., Matsui, T., Horiuchi, M., Shinagawa, M., Asahina, M., et al. (1997). p53 mutation as a potential cellular factor for tumor development 
in enzootic bovine leukosis. Vet. Immunol. Immunopathol. 55, 351-358. doi: 10.1016/S0165-2427(96)05721-2

Jimba, M., Takeshima, S. N., Matoba, K., Endoh, D., and Aida, Y. (2010). BLVCoCoMo-qPCR: quantitation of bovine leukemia virus proviral load using the CoCoMo algorithm. Retrovirology 7, 91. doi: 10.1186/1742-4690-7-91

Jimba, M., Takeshima, S. N., Murakami, H., Kohara, J., Kobayashi, N., Matsuhashi, T., et al. (2012). BLV-CoCoMo-qPCR: a useful tool for evaluating bovine leukemia virus infection status. BMC Vet. Res. 8:167. doi: 10.1186/1746-6148-8-167

Johnston, E. R., Powers, M. A., Kidd, L. C., and Radke, K. (1996). Peripheral blood mononuclear cells from sheep infected with a variant of bovine leukemia virus synthesize envelope glycoproteins but fail to induce syncytia in culture. J. Virol. 70, 6296-6303.

Juliarena, M. A., Poli, M., Sala, L., Ceriani, C., Gutierrez, S., Dolcini, G., et al. (2008) Association of BLV infection profiles with alleles of the BoLA-DRB3.2 gene. Anim. Genet. 39, 432-438. doi: 10.1111/j.1365-2052.2008.01750.x

Kashanchi, F., and Brady, J. N. (2005). Transcriptional and post-transcriptional gene regulation of HTLV-1. Oncogene 24, 5938-5951. doi: 10.1038/sj.onc.1208973

Katoh, I., Yoshinaka, Y., and Ikawa, Y. (1989). Bovine leukemia virus trans-activator p38tax activates heterologous promoters with a common sequence known as a cAMP-responsive element or the binding site of a cellular transcription factor ATF. EMBO J. 8, 497-503.

Kenyon, S. J., Ferrer, J. F., Mcfeely, R. A., and Graves, D. C. (1981). Induction of lymphosarcoma in sheep by bovine leukemia virus. J. Natl. Cancer Inst. 67, 1157-1163.

Kerkhofs, P., Heremans, H., Burny, A., Kettmann, R., and Willems, L. (1998). In vitro and in vivo oncogenic potential of bovine leukemia virus G4 protein. J. Virol. 72 , 2554-2559.

Kettmann, R., Deschamps, J., Cleuter, Y., Couez, D., Burny, A., and Marbaix, G. (1982). Leukemogenesis by bovine leukemia virus: proviral DNA integration and lack of RNA expression of viral long terminal repeat and 3' proximate cellular sequences. Proc. Natl. Acad. Sci. U.S.A. 79, 2465-2469. doi: 10.1073/pnas.79.8.2465

Klener, P., Szynal, M., Cleuter, Y., Merimi, M., Duvillier, H., Lallemand, F., et al. (2006). Insights into gene expression changes impacting B-cell transformation: cross-species microarray analysis of bovine leukemia virus tax-responsive genes in ovine B cells. J. Virol. 80, 1922-1938. doi: 10.1128/JVI.80.4.1922-1938.2006

Komori, H., Ishiguro, N., Horiuchi, M., Shinagawa, M., and Aida, Y. (1996). Predominant p53 mutations in enzootic bovine leukemic cell lines. Vet. Immunol. Immunopathol. 52, 53-63. doi: 10.1016/0165-2427(95)05538-X

Konishi, H., Kobayashi, N., and Hatanaka, M. (1984). Defective human T-cell leukemia virus in adult T-cell leukemia patients. Mol. Biol. Med. 2, 273-283.

Konnai, S., Takeshima, S. N., Tajima, S., Yin, S. A., Okada, K., Onuma, M., et al. (2003). The influence of ovine MHC class II DRB1 alleles on immune response in bovine leukemia virus infection. Microbiol. Immunol. 47, 223-232.

Konnai, S., Usui, T., Ikeda, M., Kohara, J., Hirata, T., Okada, K., et al. (2006). Tumor necrosis factor-alpha genetic polymorphism may contribute to progression of bovine leukemia virus-infection. Microbes Infect. 8, 2163-2171. doi: 10.1016/j.micinf.2006.04.017

Kono, Y., Sentsui, H., Arai, K., Ishida, H., and Irishio, W. (1983). Contact transmission of bovine leukemia virus under insect-free conditions. J. Vet. Med. Sci. 45 , 799-802.

Korber, B., Okayama, A., Donnelly, R., Tachibana, N., and Essex, M. (1991). Polymerase chain reaction analysis of defective human T-cell leukemia virus type I proviral genomes in leukemic cells of patients with adult T-cell leukemia. J. Virol. $65,5471-5476$

Koyanagi, Y., Itoyama, Y., Nakamura, N., Takamatsu, K., Kira, J., Iwamasa, T., et al. (1993). In vivo infection of human T-cell leukemia virus type I in non-T cells. Virology 196, 25-33. doi: 10.1006/viro.1993.1451

Lagarias, D. M., and Radke, K. (1989). Transcriptional activation of bovine leukemia virus in blood cells from experimentally infected, asymptomatic sheep with latent infections. J. Virol. 63, 2099-2107.

Lefebvre, L., Vanderplasschen, A., Ciminale, V., Heremans, H., Dangoisse, O., Jauniaux, J. C., et al. (2002). Oncoviral bovine leukemia virus G4 and human T-cell leukemia virus type 1 p13(II) accessory proteins interact with farnesyl pyrophosphate synthetase. J. Virol. 76, 1400-1414. doi: 10.1128/JVI.76.3.1400-1414. 2002

Leisering, A. (1871). Hypertrophy der Malpigischen Korperchen der Milz. Bericht uber das Veterinarwesen im Konigreich Sachsen 16, 15-16.
Lemasson, I., Lewis, M. R., Polakowski, N., Hivin, P., Cavanagh, M. H., Thebault, S., et al. (2007). Human T-cell leukemia virus type 1 (HTLV-1) bZIP protein interacts with the cellular transcription factor CREB to inhibit HTLV-1 transcription. J. Virol. 81, 1543-1553. doi: 10.1128/JVI.00480-06

Lewin, H. A., and Bernoco, D. (1986). Evidence for BoLA-linked resistance and susceptibility to subclinical progression of bovine leukaemia virus infection. Anim. Genet. 17, 197-207. doi: 10.1111/j.1365-2052.1986.tb03191.x

Lewin, H. A., Wu, M. C., Stewart, J. A., and Nolan, T. J. (1988). Association between BoLA and subclinical bovine leukemia virus infection in a herd of HolsteinFriesian cows. Immunogenetics 27, 338-344. doi: 10.1007/BF00395129

Mammerickx, M., Portetelle, D., and Burny, A. (1981). Experimental crosstransmissions of bovine leukemia virus (BLV) between several animal species Zbl. Vet. Med. B 28, 69-81. doi: 10.1111/j.1439-0450.1981.tb01740.x

Matsuoka, M., and Jeang, K. T. (2011). Human T-cell leukemia virus type 1 (HTLV1) and leukemic transformation: viral infectivity, Tax, HBZ and therapy. Oncogene 30, 1379-1389. doi: 10.1038/onc.2010.537

Mirsky, M. L., Olmstead, C. A., Da, Y., and Lewin, H. A. (1996). The prevalence of proviral bovine leukemia virus in peripheral blood mononuclear cells at two subclinical stages of infection. J. Virol. 70, 2178-2183.

Miyasaka, T., Takeshima, S. N., Jimba, M., Matsumoto, Y., Kobayashi, N., Matsuhashi, T., et al. (2013). Identification of bovine leukocyte antigen class II haplotypes associated with variations in bovine leukemia virus proviral load in Japanese Black cattle. Tissue Antigens 81, 72-82. doi: 10.1111/tan.12041

Murakami, H., Kuroiwa, T., Suzuki, K., Miura, Y., and Sentsui, H. (2011a). Analysis of Syk expression in bovine lymphoma and persistent lymphocytosis induced by bovine leukemia virus. J. Vet. Med. Sci. 73, 41-45. doi: 10.1292/jvms.10-0225

Murakami, H., Yamada, T., Suzuki, M., Nakahara, Y., Suzuki, K., and Sentsui, H. (2011b). Bovine leukemia virus integration site selection in cattle that develop leukemia. Virus Res. 156, 107-112. doi: 10.1016/j.virusres.2011.01.004

Murakami, K., Aida, Y., Kageyama, R., Numakunai, S., Ohshima, K., Okada, K., et al. (1994a). Immunopathologic study and characterization of the phenotype of transformed cells in sheep with bovine leukemia virus-induced lymphosarcoma. Am. J. Vet. Res. 55, 72-80.

Murakami, K., Okada, K., Ikawa, Y., and Aida, Y. (1994b). Bovine leukemia virus induces $\mathrm{CD}^{-} \mathrm{B}$ cell lymphoma in sheep despite temporarily increasing $\mathrm{CD}^{+} \mathrm{B}$ cells in asymptomatic stage. Virology 202, 458-465. doi: 10.1006/viro.1994.1362

Nagaoka, Y., Kabeya, H., Onuma, M., Kasai, N., Okada, K., and Aida, Y. (1999). Ovine MHC class II DRB1 alleles associated with resistance or susceptibility to development of bovine leukemia virus-induced ovine lymphoma. Cancer Res. 59, 975-981.

Nicot, C., Dundr, M., Johnson, J. M., Fullen, J. R., Alonzo, N., Fukumoto, R., et al. (2004). HTLV-1-encoded p30II is a post-transcriptional negative regulator of viral replication. Nat. Med. 10, 197-201. doi: 10.1038/nm984

Ohshima, K., Kikuchi, M., Masuda, Y., Kobari, S., Sumiyoshi, Y., Eguchi, F., et al. (1991). Defective provirus form of human T-cell leukemia virus type I in adult T-cell leukemia/lymphoma: clinicopathological features. Cancer Res. 51, 46394642.

Onuma, M., Honma, T., Mikami, T., Ichijo, S., and Konishi, T. (1979). Studies on the sporadic and enzootic forms of bovine leukosis. J. Comp. Pathol. 89, 159-167. doi: 10.1016/0021-9975(79)90055-0

Onuma, M., Wada, M., Yasutomi, Y., Yamamoto, M., Okada, H. M., and Kawakami, Y. (1990). Suppression of immunological responses in rabbits experimentally infected with bovine leukemia virus. Vet. Microbiol. 25, 131-141. doi: 10.1016/0378-1135(90)90072-4

Osame, M., Usuku, K., Izumo, S., Ijichi, N., Amitani, H., Igata, A., et al. (1986). HTLV-I associated myelopathy, a new clinical entity. Lancet 1, 1031-1032. doi: 10.1016/S0140-6736(86)91298-5

Panei, C. J., Takeshima, S. N., Omori, T., Nunoya, T., Davis, W. C., Ishizaki, H., et al. (2013). Estimation of bovine leukemia virus (BLV) proviral load harbored by lymphocyte subpopulations in BLV-infected cattle at the subclinical stage of enzootic bovine leucosis using BLV-CoCoMo-qPCR. BMC Vet. Res. 9:95. doi: 10.1186/1746-6148-9-95

Philpott, S. M., and Buehring, G. C. (1999). Defective DNA repair in cells with human T-cell leukemia/bovine leukemia viruses: role of tax gene. J. Natl. Cancer Inst. 91, 933-942. doi: 10.1093/jnci/91.11.933

Richard, A., and Tulasne, D. (2012). Caspase cleavage of viral proteins, another way for viruses to make the best of apoptosis. Cell Death Dis. 3, e277. doi: $10.1038 /$ cddis. 2012.18 
Robert-Guroff, M., Weiss, S. H., Giron, J. A., Jennings, A. M., Ginzburg, H. M., Margolis, I. B., et al. (1986). Prevalence of antibodies to HTLV-I, -II, and -III in intravenous drug abusers from an AIDS endemic region. JAMA 255, 3133-3137. doi: 10.1001/jama.1986.03370220095034

Sagata, N., Yasunaga, T., Ogawa, Y., Tsuzuku-Kawamura, J., and Ikawa, Y. (1984a). Bovine leukemia virus: unique structural features of its long terminal repeats and its evolutionary relationship to human T-cell leukemia virus. Proc. Natl. Acad. Sci. U.S.A. 81, 4741-4745. doi: 10.1073/pnas.81.15.4741

Sagata, N., Yasunaga, T., Ohishi, K., Tsuzuku-Kawamura, J., Onuma, M., and Ikawa, Y. (1984b). Comparison of the entire genomes of bovine leukemia virus and human T-cell leukemia virus and characterization of their unidentified open reading frames. EMBO J. 3, 3231-3237.

Sakakibara, N., Kabeya, H., Ohashi, K., Sugimoto, C., and Onuma, M. (1998) Epitope mapping of bovine leukemia virus transactivator protein tax. J. Vet. Med. Sci. 60, 599-605. doi: 10.1292/jvms.60.599

Satou, Y., Yasunaga, J., Yoshida, M., and Matsuoka, M. (2006). HTLV-I basic leucine zipper factor gene mRNA supports proliferation of adult T cell leukemia cells. Proc. Natl. Acad. Sci. U.S.A. 103, 720-725. doi: 10.1073/pnas.05076 31103

Satou, Y., Yasunaga, J., Zhao, T., Yoshida, M., Miyazato, P., Takai, K., et al. (2011). HTLV-1 bZIP factor induces T-cell lymphoma and systemic inflammation in vivo. PLoS Pathog. 7:e1001274. doi: 10.1371/journal.ppat.1001274

Schwartz, I., Bensaid, A., Polack, B., Perrin, B., Berthelemy, M., and Levy, D. (1994) In vivo leukocyte tropism of bovine leukemia virus in sheep and cattle. J. Virol. $68,4589-4596$

Schwartz, I., and Levy, D. (1994). Pathobiology of bovine leukemia virus. Vet. Res. $25,521-536$.

Starkenburg, R. J., Hansen, L. B., Kehrli, M. E. Jr., and Chester-Jones, H. (1997) Frequencies and effects of alternative DRB3.2 alleles of bovine lymphocyte antigen for Holsteins in milk selection and control lines. J. Dairy Sci. 80, 3411-3419. doi: 10.3168/jds.S0022-0302(97)76316-1

Stott, M. L., Thurmond, M. C., Dunn, S. J., Osburn, B. I., and Stott, J. L. (1991) Integrated bovine leukosis proviral DNA in T helper and T cytotoxic/suppressor lymphocytes. J. Gen. Virol. 72(Pt 2), 307-315. doi: 10.1099/0022-1317-722-307

Sulimova, G. E., Udina, I. G., Shaikhaev, G. O., and Zakharov, I. A. (1995). DNA polymorphism of the BoLA-DRB3 gene in cattle in connection with resistance and susceptibility to leukemia. Genetika 31, 1294-1299.

Szynal, M., Cleuter, Y., Beskorwayne, T., Bagnis, C., Van Lint, C., Kerkhofs, P., et al. (2003). Disruption of B-cell homeostatic control mediated by the BLV-Tax oncoprotein: association with the upregulation of $\mathrm{Bcl}-2$ and signaling through NF-kappaB. Oncogene 22, 4531-4542. doi: 10.1038/sj.onc. 1206546

Tajima, S., and Aida, Y. (2000). The region between amino acids 245 and 265 of the bovine leukemia virus (BLV) tax protein restricts transactivation not only via the BLV enhancer but also via other retrovirus enhancers. J. Virol. 74, 10939-10949. doi: 10.1128/JVI.74.23.10939-10949.2000

Tajima, S., and Aida, Y. (2002). Mutant tax protein from bovine leukemia virus with enhanced ability to activate the expression of c-fos. J. Virol. 76, 2557-2562. doi: 10.1128 /jvi.76.5.2557-2562.2002

Tajima, S., and Aida, Y. (2005). Induction of expression of bovine leukemia virus (BLV) in blood taken from BLV-infected cows without removal of plasma. Microbes Infect. 7, 1211-1216. doi: 10.1016/j.micinf.2005.04.010

Tajima, S., Ikawa, Y., and Aida, Y. (1998a). Complete bovine leukemia virus (BLV) provirus is conserved in BLV-infected cattle throughout the course of B-cell lymphosarcoma development. J. Virol. 72, 7569-7576.

Tajima, S., Zhuang, W. Z., Kato, M. V., Okada, K., Ikawa, Y., and Aida, Y. (1998b). Function and conformation of wild-type $\mathrm{p} 53$ protein are influenced by mutations in bovine leukemia virus-induced B-cell lymphosarcoma. Virology 243, 735-746. doi: 10.1006/viro.1998.9051

Tajima, S., Takahashi, M., Takeshima, S. N., Konnai, S., Yin, S. A., Watarai, S., et al. (2003a). A mutant form of the tax protein of bovine leukemia virus (BLV), with enhanced transactivation activity, increases expression and propagation of BLV in vitro but not in vivo. J. Virol. 77, 1894-1903. doi: 10.1128/JVI.77.3.1894 1903.2003

Tajima, S., Tsukamoto, M., and Aida, Y. (2003b). Latency of viral expression in vivo is not related to $\mathrm{CPG}$ methylation in the $\mathrm{U} 3$ region and part of the $\mathrm{R}$ region of the long terminal repeat of bovine leukemia virus. J. Virol. 77, 4423-4430. doi: 10.1128/JVI.77.7.4423-4430.2003
Takahashi, M., Tajima, S., Okada, K., Davis, W. C., and Aida, Y. (2005). Involvement of bovine leukemia virus in induction and inhibition of apoptosis. Microbes Infect. 7, 19-28. doi: 10.1016/j.micinf.2004.09.014

Takahashi, M., Tajima, S., Takeshima, S. N., Konnai, S., Yin, S. A., Okada, K., et al. (2004). Ex vivo survival of peripheral blood mononuclear cells in sheep induced by bovine leukemia virus (BLV) mainly occurs in $\mathrm{CD}^{-} \mathrm{B}$ cells that express BLV. Microbes Infect. 6, 584-595. doi: 10.1016/j.micinf.2004.02.014

Takeshima, S-N., and Aida, Y. (2006). Structure, function and disease susceptibility of the bovine major histocompatibility complex. Anim. Sci. J. 77, 138-150. doi: 10.1111/j.1740-0929.2006.00332.x

Tanaka, A., Takahashi, C., Yamaoka, S., Nosaka, T., Maki, M., and Hatanaka, M. (1990). Oncogenic transformation by the tax gene of human T-cell leukemia virus type I in vitro. Proc. Natl. Acad. Sci. U.S.A. 87, 1071-1075. doi: 10.1073/pnas.87.3.1071

Theilen, G. H., and Dungworth, D. L. (1965). Bovine lymphosarcoma in California 3. The calf form. Am. J. Vet. Res. 26, 696-709.

Tsukasaki, K., Tsushima, H., Yamamura, M., Hata, T., Murata, K., Maeda, T., et al. (1997). Integration patterns of HTLV-I provirus in relation to the clinical course of ATL: frequent clonal change at crisis from indolent disease. Blood 89, 948-956.

Voneche, V., Portetelle, D., Kettmann, R., Willems, L., Limbach, K., Paoletti, E., et al. (1992). Fusogenic segments of bovine leukemia virus and simian immunodeficiency virus are interchangeable and mediate fusion by means of oblique insertion in the lipid bilayer of their target cells. Proc. Natl. Acad. Sci. U.S.A. 89, 3810-3814. doi: 10.1073/pnas.89.9.3810

Weiss, R., Teich, N., Varmus, H., and Coffin, J. (1985). RNA Tumor Viruses. New York: Cold Spring Harbor Laboratory.

Willems, L., Gatot, J. S., Mammerickx, M., Portetelle, D., Burny, A., Kerkhofs, P., et al. (1995). The YXXL signalling motifs of the bovine leukemia virus transmembrane protein are required for in vivo infection and maintenance of high viral loads. J. Virol. 69, 4137-4141.

Willems, L., Gegonne, A., Chen, G., Burny, A., Kettmann, R., and Ghysdael, J. (1987). The bovine leukemia virus p34 is a transactivator protein. EMBO J. 6, 3385-3389.

Willems, L., Grimonpont, C., Kerkhofs, P., Capiau, C., Gheysen, D., Conrath, K., et al. (1998). Phosphorylation of bovine leukemia virus Tax protein is required for in vitro transformation but not for transactivation. Oncogene 16, 2165-2176. doi: 10.1038/sj.onc. 1201765

Willems, L., Heremans, H., Chen, G., Portetelle, D., Billiau, A., Burny, A., et al. (1990). Cooperation between bovine leukaemia virus transactivator protein and Ha-ras oncogene product in cellular transformation. EMBO J. 9, 1577-1581.

Willems, L., Kerkhofs, P., Dequiedt, F., Portetelle, D., Mammerickx, M., Burny, A., et al. (1994). Attenuation of bovine leukemia virus by deletion of R3 and G4 open reading frames. Proc. Natl. Acad. Sci. U.S.A. 91, 11532-11536. doi: 10.1073/pnas.91.24.11532

Williams, D. L., Barta, O., and Amborski, G. F. (1988). Molecular studies of Tlymphocytes from cattle infected with bovine leukemia virus. Vet. Immunol. Immunopathol. 19, 307-323. doi: 10.1016/0165-2427(88)90117-1

Wu, D., Takahashi, K., Murakami, K., Tani, K., Koguchi, A., Asahina, M., et al. (1996). B-1a, B-1b and conventional B cell lymphoma from enzootic bovine leukosis. Vet. Immunol. Immunopathol. 55, 63-72. doi: 10.1016/S0165-2427(96)05631-0

Wurzer, W. J., Planz, O., Ehrhardt, C., Giner, M., Silberzahn, T., Pleschka, S., et al. (2003). Caspase 3 activation is essential for efficient influenza virus propagation. EMBO J. 22, 2717-2728. doi: 10.1093/emboj/cdg279

Wyatt, C. R., Wingett, D., White, J. S., Buck, C. D., Knowles, D., Reeves, R., et al. (1989). Persistent infection of rabbits with bovine leukemia virus associated with development of immune dysfunction. J. Virol. 63, 4498-4506.

Xu, A., Van Eijk, M. J., Park, C., and Lewin, H. A. (1993). Polymorphism in BoLADRB3 exon 2 correlates with resistance to persistent lymphocytosis caused by bovine leukemia virus. J. Immunol. 151, 6977-6985.

Zanotti, M., Poli, G., Ponti, W., Polli, M., Rocchi, M., Bolzani, E., et al. (1996). Association of BoLA class II haplotypes with subclinical progression of bovine leukaemia virus infection in Holstein-Friesian cattle. Anim. Genet. 27, 337-341.

Zhang, W., Nisbet, J. W., Albrecht, B., Ding, W., Kashanchi, F., Bartoe, J. T., et al. (2001). Human T-lymphotropic virus type 1 p30(II) regulates gene transcription by binding CREB binding protein/p300. J. Virol. 75, 9885-9895. doi: 10.1128/JVI.75.20.9885-9895.2001 
Zhao, T., Satou, Y., Sugata, K., Miyazato, P., Green, P. L., Imamura, T., et al. (2011). HTLV-1 bZIP factor enhances TGF-beta signaling through p300 coactivator. Blood 118, 1865-1876. doi: 10.1182/blood-2010-12-326199

Zhao, T., Yasunaga, J., Satou, Y., Nakao, M., Takahashi, M., Fujii, M., et al. (2009). Human T-cell leukemia virus type $1 \mathrm{bZIP}$ factor selectively suppresses the classical pathway of NF-kappaB. Blood 113, 2755-2764. doi: 10.1182/blood-2008-06161729

Zhuang, W., Tajima, S., Okada, K., Ikawa, Y., and Aida, Y. (1997). Point mutation of p53 tumor suppressor gene in bovine leukemia virus-induced lymphosarcoma. Leukemia 11(Suppl 3), 344-346.

Conflict of Interest Statement: The authors declare that the research was conducted in the absence of any commercial or financial relationships that could be construed as a potential conflict of interest.
Received: 30 July 2013; accepted: 17 October 2013; published online: 08 November 2013.

Citation: Aida Y, Murakami H, Takahashi $M$ and Takeshima S-N (2013) Mechanisms of pathogenesis induced by bovine leukemia virus as a model for human T-cell leukemia virus. Front. Microbiol. 4:328. doi: 10.3389/fmicb.2013. 00328

This article was submitted to Virology, a section of the journal Frontiers in Microbiology. Copyright (c) 2013 Aida, Murakami, Takahashi and Takeshima. This is an openaccess article distributed under the terms of the Creative Commons Attribution License (CC BY). The use, distribution or reproduction in other forums is permitted, provided the original author(s) or licensor are credited and that the original publication in this journal is cited, in accordance with accepted academic practice. No use, distribution or reproduction is permitted which does not comply with these terms. 